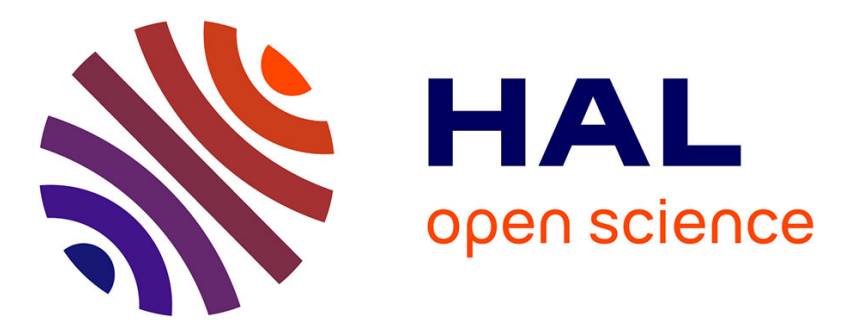

\title{
Frequency and wavelength dependencies of the electro-optic coefficients in SBN:60 single crystal
}

M. Abarkan, Jean-Paul Salvestrini, M.D. Fontana, Mireille Cuniot-Ponsard

\section{To cite this version:}

M. Abarkan, Jean-Paul Salvestrini, M.D. Fontana, Mireille Cuniot-Ponsard. Frequency and wavelength dependencies of the electro-optic coefficients in SBN:60 single crystal. Applied Physics B Laser and Optics, 2008, 91, pp.489-492. 10.1007/s00340-008-3033-3 . hal-00322257

\section{HAL Id: hal-00322257 \\ https://hal.science/hal-00322257}

Submitted on 2 Dec 2021

HAL is a multi-disciplinary open access archive for the deposit and dissemination of scientific research documents, whether they are published or not. The documents may come from teaching and research institutions in France or abroad, or from public or private research centers.
L'archive ouverte pluridisciplinaire $\mathbf{H A L}$, est destinée au dépôt et à la diffusion de documents scientifiques de niveau recherche, publiés ou non, émanant des établissements d'enseignement et de recherche français ou étrangers, des laboratoires publics ou privés.

\section{(ㅇ)(1) $\$$}

Distributed under a Creative Commons Attribution - NonCommerciall 4.0 International 


\title{
Frequency and wavelength dependencies of the electro-optic coefficients in SBN:60 single crystal
}

\author{
M. Abarkan ${ }^{1 *}$, J.P. Salvestrini ${ }^{1}$, M.D. Fontana ${ }^{1}$, M.Cuniot-Ponsard ${ }^{2}$ \\ ${ }^{1}$ Laboratoire Matériaux Optiques, Photonique et Systèmes, Université Paul Verlaine-Metz, \\ UMR CNRS 7132, Supélec, 2 rue E. Belin, 57070 Metz, France \\ ${ }^{2}$ Laboratoire Charles Fabry de l'Institut d'Optique, C.N.R.S. et Université Paris Sud, RD 128, \\ 91127 Palaiseau Cedex, France
}

\begin{abstract}
We report the dependence of the high and lowfrequency values of the linear electro-optic (EO) coefficient $r_{\mathrm{c}}=r_{33}-\left(n_{\mathrm{o}} / n_{\mathrm{e}}\right)^{3} r_{13}$ of $\mathrm{Sr}_{0.6} \mathrm{Ba}_{0.4} \mathrm{Nb}_{2} \mathrm{O}_{6}$ (SBN:60) single crystal on the laser wavelength. The EO response has been carried out from dc to $150 \mathrm{MHz}$ for four wavelengths ranging from 465 to $1321 \mathrm{~nm}$. The clamped $r^{\mathrm{S}}$ and unclamped $r^{\mathrm{T}}$ coefficients have been determined and their dispersions as a function of wavelength have been established and discussed.
\end{abstract}

\section{Introduction}

Thanks to their electro-optic (EO) and photorefractive properties, strontium barium niobate $\left(\mathrm{Sr}_{x} \mathrm{Ba}_{1-x} \mathrm{Nb}_{2} \mathrm{O}_{6}\right.$, SBN:x) mixed crystals are attractive ferroelectric materials for various applications such as holographic storage, optical switching and modulation [1-4]. Single crystals of good optical quality can be grown in several compositions $0.25<x<$ 0.75 and thus with varying properties [5]. In addition, the SBN: $x$ thin films have received more attention and considerable effort has been made in the past years to grow highquality films due to their potential application to integrated signal wave-guiding and EO devices $[6,7]$.

As the other physical properties, the EO coefficients in SBN single crystals strongly depend on the $\mathrm{Sr} / \mathrm{Ba}$ ratio $[8,9]$. Some discrepancies between these results have been reported even for the congruent composition $x=0.60$ [10-15]. It is pointed out that so far all EO data have been obtained with a low-frequency applied electric field, for which the piezoelectric effect and the space charge field can play important roles in the EO response and are strongly dependent on the sample and external conditions. Therefore it is important to measure the EO coefficient at high frequencies above the piezo-resonances. This high-frequency or constant-strain (clamped) coefficient $r^{\mathrm{S}}$ is the true EO coefficient due to the direct modulation of the indices by the applied electric field.

Fax: +33-3-87378559, E-mail: salvestr@metz.supelec.fr

* Present address: Faculté polydisciplinaire de Taza, Université Sidi Mohammed Ben Abdallah de Fès, BP 1223 Taza-Gare, Morocco
This is in contrast to the low-frequency or constant-stress (unclamped) coefficient $r^{\mathrm{T}}$, which in addition, includes the contribution of lattice deformation by the electric field. As a consequence we have carried out EO measurements as a function of frequency in a wide range and we report for the first time the clamped EO coefficient values. Likewise, as linear optical properties, the EO coefficients are expected to be strongly dependent on the wavelength $\lambda$ of the laser beam. Thus we have also measured the $\lambda$-dependence of the low and highfrequency EO coefficients for four laser wavelengths ranging from the visible to near infrared. Indeed it is important for photorefractive properties to establish this behavior. Finally, within a simple model we have achieved the $\lambda$-dependence of the EO coefficient from 0.3 up to $2 \mu \mathrm{m}$. In our study we paid attention to the EO coefficient $r_{\mathrm{c}}=r_{33}-\left(n_{\mathrm{o}} / n_{\mathrm{e}}\right)^{3} r_{13}$, which is mainly used for phase or amplitude modulation of the laser beam. The measurements were performed on a congruent SBN:60 single crystal with high optical quality obtained by a double-crucible Stepanov method [16], and using two different techniques in order to obtain reliable results.

2

\section{Experimental}

Two different methods based on the Sénarmont setup are used to measure the EO coefficients and are briefly described as follows. Within the modulation depth method (MDM) associated with the point $\mathrm{M}_{1}$ of the transfer function (Fig. 1), the so-called linear working point corresponding to $50 \%$ transmission $\left(I_{\max }-I_{\min }\right) / 2$ can be used to determine the unclamped EO coefficient as a function of frequency. Measuring the peak-to-peak amplitude $i_{\mathrm{pp}}$ of the modulated signal at the point $\mathrm{M}_{1}$, the EO coefficient can be derived from the following equation [17]:

$r_{\mathrm{eff}}(\nu)=\frac{2 \lambda d i_{\mathrm{pp}}(\nu)}{\pi n_{\mathrm{eff}}^{3} I_{0} L V_{\mathrm{pp}}(\nu)}$.

Here, $I_{0}=I_{\max }-I_{\min }$ represents the total intensity shift of the transfer function, $L$ is the length of the crystal along the beam-propagation direction, $d$ is the sample thickness along the applied electric field direction, $n_{\text {eff }}$ is the refractive index, $\lambda$ is the laser wavelength, and $V_{\mathrm{pp}}$ is the peak-to-peak value of the applied ac field at the frequency $v$.

The second method, the time response method (TRM), consists in measuring the EO crystal response to a voltage step 


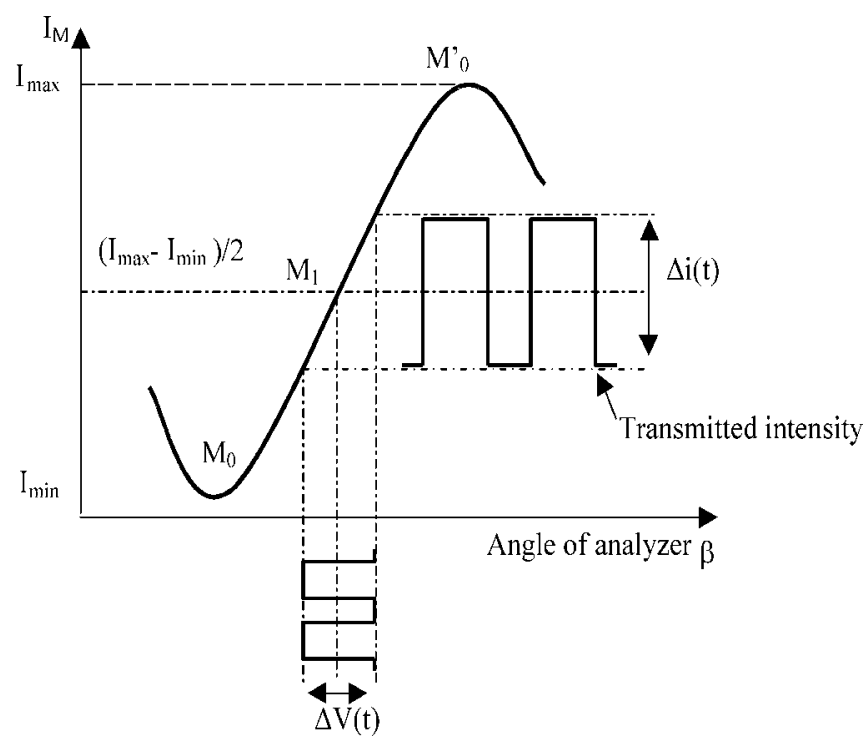

FIGURE 1 Optical transmission function of Sénarmont setup vs. the angle of the analyzer $\beta$. The point $\mathrm{M}_{0}$ is the minimum transmission point for which the frequency of the output optical signal is twice the frequency of the applied electric field. $\mathrm{M}_{1}$ is the $50 \%$ transmission point yielding the linear replica of the ac voltage

(rise time of a few nanoseconds) [18]. The optical response at a short time leads to the clamped coefficient $r^{\mathrm{S}}$, while the optical response at a longer time provides the coefficient $r^{\mathrm{T}}$. At the operating point $\mathrm{M}_{1}$, the time dependence of the variation of the transmitted beam intensity $\Delta i(t)$ is related to the applied voltage $\Delta V(t)$ by:

$\Delta i(t)=\frac{\pi n_{\mathrm{eff}}^{3} I_{0} L}{2 \lambda d} r_{\mathrm{c}} \bigotimes \Delta V(t)$,

where $\bigotimes$ is the convolution operator. The frequency dispersion of the EO coefficient can be derived from the ratio of the quantities $\Delta i(v)$ and $\Delta V(v)$, which are obtained by the $Z$ transform of the measured signals $\Delta i(t)$ and $\Delta V(t)$ :

$r_{\mathrm{eff}}(\nu)=\frac{2 \lambda \mathrm{d} \Delta i(v)}{\pi n_{\mathrm{eff}}^{3} I_{0} L \Delta V(v)}$.

We have shown [18] that this technique allows to obtain the frequency dispersion of the EO coefficient from dc up to at least $150 \mathrm{MHz}$. This maximum depends only on the rising time of the voltage pulse. It is to be mentioned that the values of the coefficients obtained by these two techniques are absolute values.

\section{$3 \quad$ Results and discussion}

We show in Fig. 2 data of both the applied voltage and the optical signal (for two different time scales) recorded within the TRM at a wavelength of $633 \mathrm{~nm}$. In the long-time range the optical signal oscillates with a period that corresponds to the main piezo-electric frequency resonances. The oscillations are vanishing for time longer than several hundred $\mu s$. They disappeared for time shorter than $0.2 \mu$ s since the acoustic waves need more time to propagate across the crystal. The amplitude values of the signal at short time and long

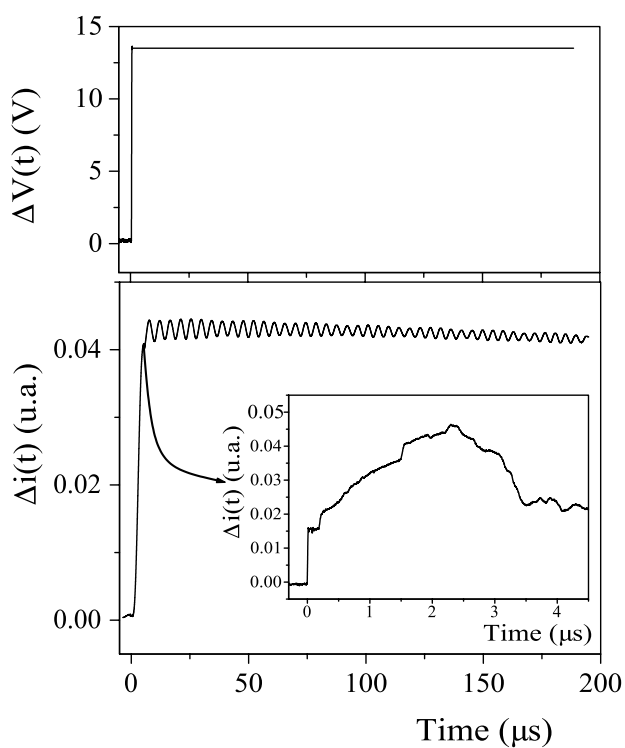

FIGURE 2 Measured response to a step voltage at different time scales of the EO coefficient $r_{\mathrm{c}}$ in the SBN:60 single crystal. Measurements were performed at the wavelength of $632.8 \mathrm{~nm}$

time are nearly constant and correspond to the EO coefficients $r_{\mathrm{c}}^{\mathrm{S}}$ and $r_{\mathrm{c}}^{\mathrm{T}}$, respectively.

The frequency dispersion of the EO coefficient $r_{\mathrm{c}}$ can be derived, according to (3), from the ratio of $\Delta i(v)$ and $\Delta V(v)$, which were obtained by the Z-transform of the $\Delta i(t)$ and $\Delta V(t)$ signals shown in Fig. 2. The results at the wavelength of $633 \mathrm{~nm}$, as well as those corresponding to the dielectric permittivity measured along the $c$-axis, are plotted in Fig. 3. The dependencies of the EO coefficient $r_{\mathrm{c}}$ and the dielectric permittivity $\varepsilon_{33}$ are flat on both sides of the piezo-electric resonances. The values of the flat parts at low and high frequency give $r_{\mathrm{c}}^{\mathrm{S}}=155 \mathrm{pm} / \mathrm{V}$ and $r_{\mathrm{c}}^{\mathrm{T}}=210 \mathrm{pm} / \mathrm{V}$, respectively. The low-frequency values of the coefficient $r_{\mathrm{c}}^{\mathrm{T}}$ as obtained by the

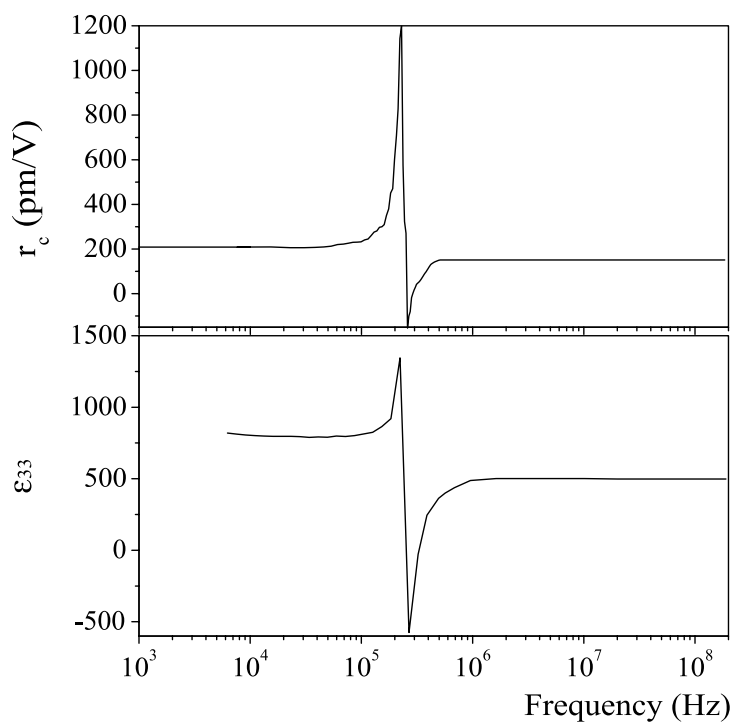

FIGURE 3 Frequency dispersions of the EO coefficient $r_{\mathrm{c}}$ as deduced from time response measurements and of the dielectric permittivity $\varepsilon_{33}$ measured within an impedance analyzer 


\begin{tabular}{lccc}
\hline $\begin{array}{l}\text { EO coefficient } \\
(\mathrm{pm} / \mathrm{V})\end{array}$ & $\begin{array}{c}\text { Present } \\
(\lambda=1.3 \mu \mathrm{m})\end{array}$ & $\begin{array}{c}\text { Work } \\
(\lambda=633 \mathrm{~nm})\end{array}$ & $\begin{array}{c}\text { Literature } \\
(\lambda=633 \mathrm{~nm})\end{array}$ \\
\hline$r_{\mathrm{c}}^{\mathrm{T}}$ & $167 \pm 10$ & $210 \pm 13$ & $190^{\mathrm{a}}[11], 200^{\mathrm{a}}[1], 190^{\mathrm{a}}[8], 304[10]$ \\
$r_{\mathrm{c}}^{\mathrm{S}}$ & $117 \pm 6$ & $155 \pm 10$ & - \\
$r_{33}^{\mathrm{T}}$ & $197 \pm 20$ & $223^{\mathrm{b}}$ & $235[11], 237[1], 235[8]$ \\
$r_{13}^{\mathrm{T}}$ & $27 \pm 3$ & $30^{\mathrm{b}}$ & $46.7[11], 37[1], 47[8]$ \\
$r_{\mathrm{c}}^{\mathrm{a}}=r_{\mathrm{c}}^{\mathrm{T}}-r_{\mathrm{c}}^{\mathrm{S}}$ & $50 \pm 10$ & $55 \pm 13$ & $57-60^{\mathrm{c}}[1,19]$ \\
\hline
\end{tabular}

TABLE 1 Absolute values of the EO coefficients $r_{13}^{\mathrm{T}}, r_{33}^{\mathrm{T}}, r_{\mathrm{c}}^{\mathrm{T}}, r_{\mathrm{c}}^{\mathrm{S}}$ and $r_{\mathrm{c}}^{\mathrm{a}}$ in SBN:60 measured at 633 and $1321 \mathrm{~nm}$ and at room temperature

a Values deduced from $r_{13}^{\mathrm{T}}$ and $r_{33}^{\mathrm{T}}$ measurements;

b Values deduced according to the model described by (4);

c Values derived from elasto-optic and piezo-electric coefficients reported in the literature via the calculation of the relationship $\left(\left(p_{11}+p_{12}\right)-2\left(\frac{n_{0}}{n_{\mathrm{e}}}\right)^{3} p_{31}\right) d_{31}+\left(p_{13}-\left(\frac{n_{\mathrm{o}}}{n_{\mathrm{e}}}\right)^{3} p_{33}\right) d_{33}$

two different methods (TRM and MDM techniques) are close to each other within the experimental errors, and are in agreement with the values deduced (using the relation $r_{\mathrm{c}}=r_{33}-$ $\left.\left(n_{\mathrm{o}} / n_{\mathrm{e}}\right)^{3} r_{13}\right)$ from the measurements of $r_{13}^{\mathrm{T}}$ and $r_{33}^{\mathrm{T}}$ reported in the literature (see Table 1). On the contrary, we note a discrepancy between our results and those obtained in [10] by a direct measurement. We stress that the frequency dispersion of the EO coefficient has not yet been investigated and the high-frequency EO coefficient $r_{\mathrm{c}}^{\mathrm{S}}$ is thus for the first time reported. Its value, equal to $155 \pm 10 \mathrm{pm} / \mathrm{V}$, is very large so that the SBN crystal can be efficiently used for EO modulation above the piezo-resonances within a large frequency range. Both EO and dielectric coefficients exhibit the same behavior with frequency. This shows that both properties are linked and the piezo-electric is responsible for the large step between low and high-frequency values.

For the EO coefficient this difference between $r_{\mathrm{c}}^{\mathrm{T}}$ and $r_{\mathrm{c}}^{\mathrm{S}}$ is found to be $r_{\mathrm{c}}^{\mathrm{a}}=55 \pm 13 \mathrm{pm} / \mathrm{V}$, which provides the acoustic contribution to the EO coefficient. This contribution arises from the combination of piezo-electric and elasto-optic effects and can be calculated from the associated coefficients. From the values of elasto-optic and piezo-electric coefficients reported in the literature $[1,19]$ for SBN:50 and SBN:75 we estimated the value of $r_{\mathrm{c}}^{\mathrm{a}}$ to 57 and $60 \mathrm{pm} / \mathrm{V}$ respectively, close to our direct experimental data in SBN:60 (see Table 1).

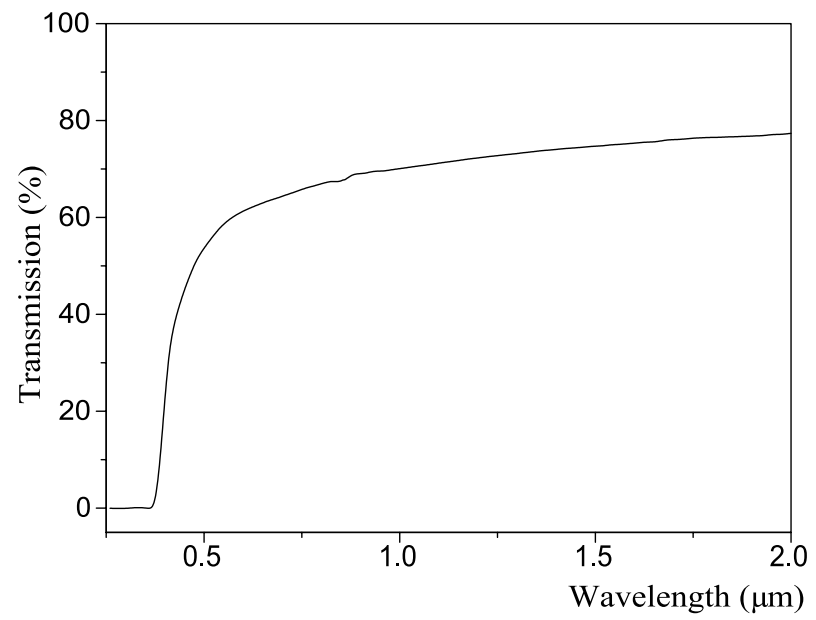

FIGURE 4 Transmission spectra of SBN:60 single crystal obtained for unpolarized light propagating along the $x$-axis of the crystal. The Fresnel losses are not taken into account
This consistency reinforces the validity of our experimental results obtained at high frequency since $r_{\mathrm{c}}^{\mathrm{S}}=r_{\mathrm{c}}^{\mathrm{T}}-r^{\mathrm{a}}$. In addition with the direct measurement of $r_{\mathrm{c}}$ we have obtained the values of $r_{13}^{\mathrm{T}}$ and $r_{33}^{\mathrm{T}}$ by means of a Mach-Zehnder interferometer and the MDM method. We found $r_{13}^{\mathrm{T}}=27 \mathrm{pm} / \mathrm{V}$ and $r_{33}^{\mathrm{T}}=197 \mathrm{pm} / \mathrm{V}$ at the wavelength of $1341 \mathrm{~nm}$. Using the relation $r_{\mathrm{c}}=r_{33}-\left(n_{\mathrm{o}} / n_{\mathrm{e}}\right)^{3} r_{13}$, these values yield $r_{\mathrm{c}}^{\mathrm{T}}=$ $168 \mathrm{pm} / \mathrm{V}$, in good agreement with this measured directly at $1321 \mathrm{~nm}, r_{\mathrm{c}}^{\mathrm{T}}=167 \mathrm{pm} / \mathrm{V}$.

The linear optical properties of SBN strongly depend on the wavelength in the visible range, as shown by the refractive indices [20] and the transmission spectra reported in Fig. 4. Therefore the dependencies of both $r_{\mathrm{c}}^{\mathrm{T}}$ and $r_{\mathrm{c}}^{\mathrm{S}} \mathrm{EO}$ coefficients were investigated for several wavelengths: $465 \mathrm{~nm}, 514 \mathrm{~nm}$ of an Ar laser, $633 \mathrm{~nm}$ of a He-Ne laser, and $1321 \mathrm{~nm}$ of a Nd:YAG laser. The complete set of results is reported in Fig. 5. We note a strong increase of the $r_{\mathrm{c}}^{\mathrm{T}}$ and $r_{\mathrm{c}}^{\mathrm{S}}$ values for wavelengths approaching the absorption edge (see Fig. 4). Moreover, this increase is even larger for $r_{\mathrm{c}}^{\mathrm{T}}$ than for $r_{\mathrm{c}}^{\mathrm{S}}$, indicating that the acoustic contribution $r_{\mathrm{c}}^{\mathrm{a}}$ is dependent on the wavelength.

From these measurements, it is possible to establish the $\lambda$-dependence of the EO coefficients, within a simple model [21] based on non-linear optical (NLO) interactions [22]. It is well known that the EO process can be treated

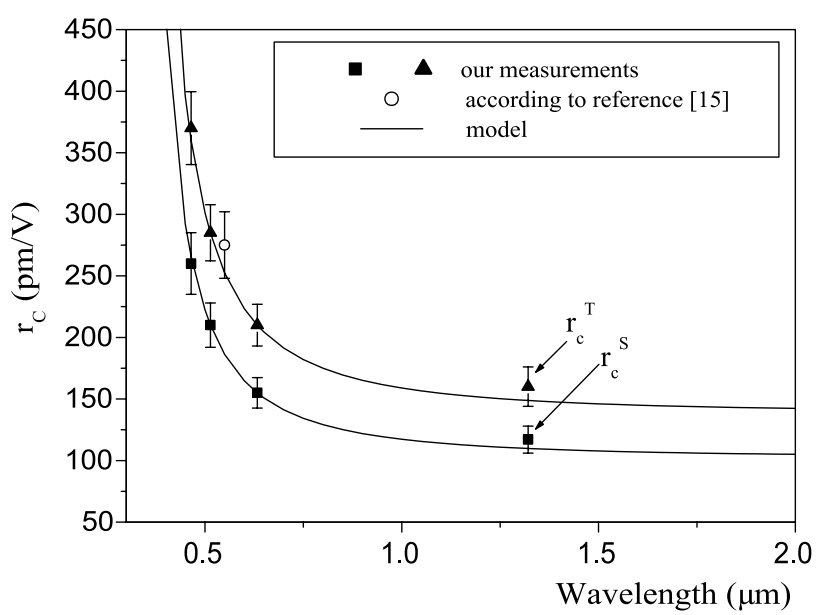

FIGURE 5 Dispersion of the effective EO coefficient $r_{\mathrm{c}}^{\mathrm{S}}$ and $r_{\mathrm{c}}^{\mathrm{T}}$ in SBN:60 single crystal. The dots correspond to the measured values and the line is the calculated dispersion obtained via our model 


\begin{tabular}{lccccc}
\hline $\begin{array}{l}\text { Polarization direction } \\
\text { of the light-beam }\end{array}$ & $A$ & $\begin{array}{c}B \\
\left(\mu \mathrm{m}^{2}\right)\end{array}$ & $\begin{array}{c}C \\
\left(\mu \mathrm{m}^{2}\right)\end{array}$ & $\begin{array}{c}\lambda_{0 i} \\
(\mu \mathrm{m})\end{array}$ & $\begin{array}{c}a_{i j k}^{\mathrm{T}} \\
\left(\mathrm{mV}^{-1} \mathrm{~s}^{-2}\right)\end{array}$ \\
\hline$X$ & 5.002 & 0.1272 & 0.052 & 0.35 & $\begin{array}{c}a_{i j k}^{\mathrm{S}} \\
\left(\mathrm{mV}^{-1} \mathrm{~s}^{-2}\right)\end{array}$ \\
\hline$Z$ & 4.8866 & 0.1187 & 0.048 & 0.35 & $17.3 \times 10^{20}$ \\
1
\end{tabular}

TABLE 2 Values of the parameters used in our study. A, B and C are the Sellmeier coefficients [20]. The terms $\lambda_{0 i}, a_{i j k}^{\mathrm{T}}$ and $a_{i j k}^{\mathrm{S}}$ are the parameter values of the model used to fit the wavelength dispersion of the clamped and unclamped $r_{\mathrm{c}}$ EO coefficient in the SBN:60 single crystal

as a NLO interaction with a low-frequency (modulation) electric field and a high-frequency (laser) field so that the EO coefficient $r_{i j k}(\lambda)$ is a particular case of the non-linear second-order susceptibility $\chi^{(2)}(\lambda+v ; \lambda ; v)$, in which $v$ is the modulation frequency. We can show that [21] the wavelength dispersion of the clamped and unclamped EO coefficient can be described by:

$r_{i j k}^{\mathrm{T}(\mathrm{S})}(\lambda)=-\frac{\left(n_{j}^{2}(\lambda)-1\right) \lambda_{0 i}^{2} \lambda^{2}}{2 \pi^{2} c^{2} n_{i}^{2}(\lambda) n_{j}^{2}(\lambda)\left(\lambda^{2}-\lambda_{0 i}^{2}\right)} a_{i j k}^{\mathrm{T}(\mathrm{S})}$,

where $a_{i j k}^{\mathrm{T}(\mathrm{S})}$ is a parameter depending on the modulation frequency only, so that it has different values whether the modulation frequency is below $\left(r^{\mathrm{T}}\right)$ or above $\left(r^{\mathrm{S}}\right)$ piezo-resonances. The term $c$ is the speed of the light in vacuum and $\lambda_{0 i}$ represents the wavelengths corresponding to the different absorption edges.

In (4) $n(\lambda)$ is the refractive index dispersion described by a conventional Sellmeier equation as:

$n^{2}(\lambda)=A+\frac{B}{\lambda^{2}-\lambda_{0}^{2}}-C \lambda^{2}$,

where $A, B$ and $C$ are the Sellmeier parameters. It is to be pointed out that our model described by (4) provides the wavelength dependence of the linear EO coefficient from the knowledge of the dispersion of the linear indices, with only one adjustable parameter. First we obtain the dispersion of the refractive indices derived from the data reported in the literature [20] and the parameter values reported in Table 2. Then from the values of both EO coefficients $r^{\mathrm{T}}$ and $r^{\mathrm{S}}$ measured at $1.3 \mu \mathrm{m}$, we obtain the values of $a_{i j k}^{\mathrm{T}}$ and $a_{i j k}^{\mathrm{S}}$, respectively, and we derive the wavelength dependencies plotted in Fig. 5. A remarkable agreement between experimental and calculated values is achieved for both low and high-frequency coefficients. It is also to be noticed that our calculated value of $r_{\mathrm{c}}^{\mathrm{T}}$ at $549 \mathrm{~nm}$ is consistent with the value deduced from the measurements of $r_{13}^{\mathrm{T}}$ and $r_{33}^{\mathrm{T}}$ at $\lambda=549 \mathrm{~nm}$ by Trivedi et al. [15]. Furthermore, we derived, from our model and the procedure described above, the values of the EO coefficients $r_{13}^{\mathrm{T}}$ and $r_{33}^{\mathrm{T}}$ at $\lambda=633 \mathrm{~nm}$. These values, reported in Table 1, are in good agreement with those of the literature and thus prove out the validity of our model.

\section{Conclusion}

We reported reliable measurements of the electrooptic coefficients in SBN:60. Especially, the high-frequency value of the EO coefficient $r_{\mathrm{c}}$ is provided for the first time, and its dependence on the wavelength, in the visible and near infrared (up to $2 \mu \mathrm{m}$ ) range, is determined within a simple model and data recorded at four discrete wavelengths.

ACKNOWLEDGEMENTS The authors would like to acknowledge G. Roosen, from the Institut d'Optique - Graduate School, for the kind supply of the SBN:60 crystal.

\section{REFERENCES}

1 H.Y. Zhang, X.H. He, Y.H. Shih, S.H. Tang, Opt. Commun. 86, 509 (1991)

2 F. Micheron, G. Bismuth, Appl. Phys. Lett. 20, 79 (1972)

3 Y. Quiao, S. Orlov, D. Psaltis, R.R. Neurgaonkar, Opt. Lett. 18, 1004 (1993)

4 L. Zhang, Z. Shao, X. Mu, H. Chen, M. Jiang, Opt. Commun. 123, 587 (1996)

5 A.A. Ballmann, S.K. Kurtz, H. Brown, J. Cryst. Growth 10, 185 (1971)

6 M. Cuniot-Ponsard, J.M. Desvignes, A. Bellemain, J. Mater. Sci. 41, $5302(2006)$

7 Y. Tan, F. Chen, H.-J. Zhang, Opt. Express 15, 16696 (2007)

8 R.A. Vasquez, M.D. Ewbank, R.R. Neurgaonkar, Opt. Commun. 80, 253 (1991)

9 C. Huang, J.H. Liu, Y. Liu, M. Gu, A.S. Bhalla, R. Guo, Proc. SPIE 5911, 59110 Y (2005)

10 A.K. Ghatak, S. Thyagarajan, Optical Electronics (Cambridge University Press, Cambridge, 1989)

11 S. Ducharme, J. Feinberg, IEEE J. Quantum Electron. QE-23, 2116 (1987)

12 J. Fox, J. Appl. Phys. 44, 254 (1973)

13 M. Ingold, P. Gunter, Soc. Photo. Opt. Instrum. Eng. 1018, 94 (1988)

14 U.B. Dörfler, R. Piechatzek, T. Woike, M.K. Imlau, V. Wirth, L. Bohaty, T. Volk, R. Pankrath, M. Wöhlecke, Appl. Phys. B 68, 843 (1999)

15 D. Trivedi, P. Tayebati, M. Tabat, Appl. Phys. Lett. 68, 3227 (1996)

16 S. Takekawa, Y. Furukawa, M. Lee, K. Kitamura, J. Cryst. Growth 229, $238(2001)$

17 L. Guilbert, J.P. Salvestrini, M.D. Fontana, H. Hassan, IEEE J. Quantum Electron. QE-35, 273 (1999)

18 M. Abarkan, J.P. Salvestrini, M. Aillerie, M.D. Fontana, Appl. Opt. 42, 2346 (2003)

19 N.M. Shorrocks, R.W. Whatmore, S.T. Liu, J. Phys. D Appl. Phys. 15, 2469 (1982)

20 C. David, A. Tunyagi, K. Betzler, M. Wöhlecke, Phys. Stat. Solidi B 244, 2127 (2007)

21 M.D. Fontana, J.P. Salvestrini, M. Abarkan, Phys. Rev. B (submitted 2008)

22 N. Blombergen, Nonlinear Optics (Benjamin, New York, 1965) 